\title{
Effect of isolated mesenchymal stem cells on the liver injury of rats
}

Mohga M. Al-Essawy ${ }^{1 *}$; Mahmoud M. Gabr ${ }^{1}$; Mai M.El-Keiy²; Tarek M.Mohamed²

${ }^{1}$ Urology and Nephrology Center, Mansoura University, Mansoura, Egypt

${ }^{2}$ Department of Biochemistry, Faculty of Science, Tanta University, Tanta, Egypt

\section{ART I CLE INFO}

Colorectal cancer, HCT-116,

Nanocurcumin, MTT assay, P53,

BAX, BCL2, Caspase-9.

\section{ABSTRACT}

Background: This study aimed to evaluate the ability of mesenchymal stem to treat liver injury. Liver transplantation and surgical treatment may be one of the good available solutions for liver injuries. However, it is painful and limited due to shortage of donor organs and high medical costs. Mesenchymal stem cells (MSCs) can serve as an autologous treatment to the liver injury. This study aims to evaluate the ability of MSCs to treat liver injury. Rat MSCs were isolated, expanded for 4 passages. Then they were injected into the tail vein of Sprague Dawley rats which were previously inducted to liver fibrosis with carbon tetrachloride ( $\left.\mathrm{CCL}_{4}\right)$. After and before cell injection, the biochemical analysis of liver function tests and the immunohistochemistry were tested for the liver tissue after 6 weeks of disease induction. Conclusion: AD-MSCs have a promising effect against CCL4 induced liver fibrosis as well as enhancing liver function tests.

(C) 2020 Publisher All rights reserved.

Corresponding author: Mobile: +201010080272 ,

E-mail address: mohgaalessawy@ gmail.com 


\section{INTRODUCTION}

Chronic hepatic injury such as liver fibrosis is regarded as a fetal disease (1). Liver fibrosis can result in biochemical deviations such as decrease albumin synthesis, cholesterol synthesis, and insulin resistance. Cholestasis is evidence for an increase in alkaline phosphatase (ALP) and Gamma-glutamyl (GGT) levels. Any type of liver injury may cause portal hypertension (an increase in blood pressure within the portal vein and its tributaries), since they may bleed profusely, frequently resulting in patient death ${ }^{(2,3)}$. Transplantation is currently the only reliable treatment for end stage of hepatic fibrosis ${ }^{(4)}$. But there are many complications are associated with transplantation as a shortage of organs and other transplantation complications, which forces us to find another therapeutic solution. Mesenchymal stem cells can help to solve that as it prevent the fibrotic lesions (5) or improve liver functions in experimental fibrosis models ${ }^{(6)}$. Adipose derived mesenchymal stem cells (AD-MSCs) are regarded as an adult mesenchymal stem cells source, presents a similar multiple-linage differentiating potential to bone marrow MSCs ${ }^{(7)}$. MSCs considered as an alternative improver for liver injury. Stem cells therapy plays an important role in regenerative medicine due to its benefits in the replacement and improvement of damaged tissue functions and understanding of cell development. It was expected that stem cells therapy provide an alternative source in the treatment of certain degenerative and genetic disorders such as neurological diseases, autoimmune disease, wound healing, cardiac disease, liver disease, metabolic disorders and bone disease (8). In the current study, the hypothesis is that transplantation of $\mathrm{AD}$ MSCs may revoke CCL4 induced liver fibrogenesis in Sprague-Dawley (SD) rats and recover liver functions which were tested.

\section{MATERIAL AND METHODS}

\section{Isolation and Expansion of AD-MSCS}

AD-MSCs were isolated according to a method described by Safford et al (9). Adipose tissue (100 mg) was obtained from the inguinal fat of SD rats, then was digested in Hank's balanced salt solution containing $0.075 \%$ collagenase type I (Gibco, Carlsbad, CA, USA) at $37{ }^{\circ} \mathrm{C}$ for $45 \mathrm{~min}$. After dissociation, the digested solution was subsequently filtrated with a $100 \mu \mathrm{m}$ cell strainer and centrifuged for ten minutes at $1800 \mathrm{rpm}$ at room temperature. After that, complete media which was composed of dulbecco's modified Eagle's medium (DMEM; Gibco, USA) with $10 \%$ fetal bovine serum (FBS; Gibco, USA) and 1\% penicillin/ streptomycin was added to cells. Finally, the suspended cells were transferred to a tissue culture flask and incubated in 5\% $\mathrm{CO} 2$ at $37{ }^{\circ} \mathrm{C}$. After 3 days, the old complete medium was replaced with new one. When the cultured MSCs were reached to $80 \%$ confluence, they were seeded at a ratio of 1:2. This step was repeated again till third passage. At this point, the cells were spindle-shaped, displayed a fibroblast-like appearance and used for further experiments $^{(10)}$.

\section{Induction of liver fibrosis}


The required approvals were obtained from the ethical committee of Animal Experiment of the Tanta University. 8-week-old male Sprague-Dawley (SD) rats whose weights were around $180 \mathrm{gm}$ were housed in a controlled temperature of $25{ }^{\circ} \mathrm{C}$ and humidity $\sim 70 \%$.After a period of adaptation on basal diet, healthy 30 Sprague Dawley rats were divided into 3 experimental groups: 10 animals for each group.

1. Group (1): 10 rats were served as a normal control group.

2. Group (2): 10 rats were given Intra peritoneal i.p. dose of carbontetrachloride $\left(\mathrm{CC}_{4}\right)$ in olive oil $(1 \mathrm{ml} / \mathrm{Kg})$ twice a week for 4 weeks to induce fibrosis in the liver ${ }^{(11)}$.These rats were served as diseased group.

3. Group (3): 10 rats were injected with $\mathrm{CC}_{4}$ as in group 2 and then they were treated with intravenous injection of $3 \mathrm{x}$ $10^{6}$ cells of AD-MSCs.CCL4 Intraperitoneal (i.p.) injections were performed twice a week for 12 weeks to induce liver fibrosis. The dose of $\mathrm{CCL}_{4}$ (diluted in olive oil 1:1) was $1 \mathrm{~mL} / \mathrm{kg}{ }^{(12)}$. Liver function blood tests were performed to the rats after 12 weeks of $\mathrm{CCL}_{4}$ administration. Ten normal rats were regarded as a negative control group to define the normal range of aspartate aminotransferase (AST), aminotransferase (ALT), gamma-glutamyl (GGT) and alkaline phosphatase activity (ALP). The rats with abnormal AST, ALT, GGT, and ALP were treated with AD-MSCs (treated group). AD-MSCs at $4^{\text {th }}$ passage were used for treatment, as $3 \times 10^{6}$ cells were suspended at $0.5 \mathrm{ml}$ saline per rat and injected through the tail vein. The untreated group was injected with saline. Recovery of administrated rats with $\mathrm{CCL}_{4}$ was notable after AD-MSCs injection. The rats were sacrificed after 12 weeks from injection with $\mathrm{CCL}_{4}$, blood and liver samples were collected

\section{Transplantation of AD-MSCs}

At confluence $90 \%$, cells were sub-cultured from one flask into 2 flasks in a process called trypsinization (passage) and in this state cells became in passage one (P1). Cells took about one week till reached $\mathrm{P} 1$. The old media was removed by aspiration using sterile pipette then the cultured cells were washed by $10 \mathrm{ml}$ PBS.After that $10 \mathrm{ml}$ of (0.05\% trypsin, $0.02 \%$ EDTA) was added and the flasks were checked under inverted microscope till cells were separated from each other but they were still attached to the flask. At this stage, the shape of the cells changed from spindle to spherical. The trypsin was removed and the cells were incubated in a $\mathrm{CO}_{2}$ incubator for about 2 minutes (13). The incubated flasks were checked under an inverted microscope Twenty $\mathrm{ml}$ of complete media was added. The feeding process was performed after 3 days with daily examination under an inverted microscope till cells reached confluence $90 \%$ after about 4 days from P1 and at this point cells were trypsinized and became in P2. The culture of the cells was continued until passage $4(\mathrm{P} 4)$. At $\mathrm{p} 4$ the cells were typsynized and collected for cell viability and count detection, then $\left(3 \times 10^{6}\right.$ per rat) in a volume of $0.2 \mathrm{ml}$ PBS was injected via tail vein of by 26 -gouge needle. Rats of groups (3) were used as cells recipient. The recipient rats were anesthetized with pentobarbital $(50 \mathrm{mg} / \mathrm{ml})$ 
at a dose of $0.1 \mathrm{ml} / 100 \mathrm{gm}$ of body weight intraperitoneally.

\section{Biochemical analysis}

Within one hour of blood collection after scarification, the serum was separated by centrifugation and stored at $-80^{\circ} \mathrm{C}$ for further analysis. Using an Automated Chemical Analyzer (7600; Hitachi, Tokyo, Japan) according to the manufacturer's instructions to determine ALT, AST, GGT, and ALP serum levels.

\section{Statistical analysis}

Statistical analysis was performed using SPSS 13.0. Measurements were performed three times, and results were expressed as the mean $\pm \mathrm{SD}$. The difference regarded as statistically significant if the p-value was less than 0.05 .

\section{RESULTS}

\section{Morphological analysis:}

On the 3rd day of isolation, small spindleshaped MSCs started to appear adhered to the plastic surface of the flask with large numbers of non-MSCs present. On the 6th day, the number of MSCs increased, and the cells became larger and more spindleshaped. From the 2nd feed until passage 1(P1) MSCs proliferated more and more till reaching a confluence of 90 (Figure 1).

\section{Outcomes of biochemical parameters:} Serum ALT, AST, GGT and ALP activities showed highly significant elevation in rats induced liver fibrosis. Rats of treated group after 6 weeks of injection of AD-MSC showed a highly significant decrease $(P<0.0001)$ in ALT, AST, GGT and ALP serum levels as compared with the treated group but still higher than that of the negative control group (Table 1).

\section{Concealment of Liver Fibrosis after AD- MSCs Injection}

Hematoxylin and eosin were used to confirm that the injection of AD-MSC to the tail vein of rats with fibrotic liver tissue caused improvement comparing to diseased with normal liver as control (Figure 2A). Analysis under microscope showed that there were scattered stem cells in liver tissue (Figure 2B). This refers to the injected stem cells reached the liver tissue. After 12 weeks of $\mathrm{CCL}_{4}$ administration (untreated group), liver biopsy showed architecture with cloudy swelling of hepatocytes, fatty degeneration and portal fibrosis (Figure 2C). AD-MSCs injection significantly relieves necrosis and subs equently suppressed septal fibrotic defect. Hepatic tissues at six weeks after implantation of stem cells showed minimal portal fibrosis, mostly normal liver architecture (Figure 2D).

\section{DISCUSSION}

In the current study, we investigated the effect of AD-MSCs on liver fibrosis induced by carbon tetrachloride ( $\left.\mathrm{CCL}_{4}\right)$. Liver disease is still one of horrific issues in the world today. According to world health statistics, the strategies for liver disease treatments still have many limitations, because of the pathogenesis of liver diseases as well as the causative role of oxidative stress and inflammation ${ }^{(\mathbf{1 4}, 15)}$.Liver diseases, 
for instance, sever liver fibrosis MSCs are recently consider consecutive treatment for transplantation of liver. In other cases of severe liver injury such as hepatocellular carcinoma ischemia-reperfusion injury, MSCs have also been reported to be a potential solution (16). A large number of clinical researches have demonstrated that stem cell transplantation is a promising approach for the treatment of liver fibrosis (17). In the current study, we isolate MSCs from rat adipose tissue because it is enriched with multipotent MSCs and considered to be a good source for autologous stem cell transplantation. AD-MSCs have the ability of self-renewal, proliferation, and differentiate into multiple cell lineages. ADMSCs can be easily isolated from subcutaneous fat tissue through a safe liposuction procedure and have a high frequency and proliferative rate than BMMSCs (18).

One of the most commonly used hepatotoxins is $\mathrm{CCL}_{4}$ in many experimental studies of liver diseases. Its hepatotoxic effects are largely due to its active metabolite, trichloromethyl radicals. These activated radicals bind covalently to the macromolecules and induce peroxidative degradation of membrane lipids of endoplasmic reticulum rich in polyunsaturated fatty acids. This leads to the formation of lipid peroxides followed by pathological changes such as depression of protein synthesis and elevated levels of serum marker enzymes such as ALT, AST and ALP ${ }^{(20)}$.

The results of the present study confirmed that $\mathrm{CCL}_{4}$ is able to elevate the levels of serum marker enzymes ALT, AST and ALP in the diseased group which indicated that the liver tissue was damaged, but MSCs treatment showed nearly normal level of enzymes activities that proved MSCs can reduce the liver injury in the treated group. Moreover, Histological examination illustrated the same propensity, which stands with the Rabani et al study (20), which reported that MSCs tail vein injection helped in liver fibrosis treatment.

The tail vein injection was reported to be more effective than portal vein injection that has been reported by Kim and coworkers ${ }^{(21)}$.

In conclusion the recent results suggest that AD-MSCs were easily accessible and enhance microcirculation and ameliorate liver fibrosis.

\section{REFERENCES}

1. Kral, J. G. et al. (2004) 'Effects of surgical treatment of the metabolic syndrome on liver fibrosis and cirrhosis', Surgery, 135(1), pp. 4858. doi: 10.1016/j.surg.2003.10.003.

2. G, P., B, V. and DVHS, S. (2019) 'Biomarkers to Assess Liver Function in Various Types of Liver Diseases', International Journal of Clinical and Biomedical Research, pp. 28-31. doi: 10.31878/ijcbr.2019.52.06.

3. Yuan, X. X. et al. (2019) 'Clinical characteristics of non-alcoholic fatty liver disease in Chinese adult hypopituitary patients', World Journal of Gastroenterology, 25(14), pp. 1741-1752. doi: 10.3748/wjg.v25.i14.1741.

4. Perry, M. T. et al. (2016) 'Point shear wave elastography in 
assessment of hepatic fibrosis: Diagnostic accuracy in subjects with native and transplanted livers referred for percutaneous biopsy', Ultrasound Quarterly, 32(3), pp. 201207.doi:10.1097/RUQ.00000000 00000219.

5. Fernández-Colino, A. et al. (2019) 'Fibrosis in tissue engineering and regenerative medicine: treat or trigger?', Advanced Drug Delivery Reviews, 146, pp. 17-36. doi: 10.1016/j.addr.2019.07.007.

6. Sakaida I, Terai S, Yamamoto N, et al: Transplantation of bone marrow cells reduces CCL4-induced liver fibrosis in mice. Hepatology 2004, 40 (6):1304-1311.

7. Deans RJ, Moseley AB: Mesenchymal stem cells: biology and potential clinical uses. Exp Hematol 2000, 28:875-884.

8. Srijaya, T.C.; Ramasamy, T. S. and Abu-Kasim. N. H. (2014): Advancing stem cell therapy from bench to bedside: lessons from drug therapies. Journal of Translational Medicine, 12: 243-249.

9. Safford KM, Hicok KC, Safford SD, et al: Neurogenic differentiation of murine and human adipose-derived stromal cells. Biochem Biophys Res Commun 2002, 294:371-379.

10. 10- Dominici M., Le Blanc K., Mueller I., Slaper-Cortenbach I., Marini F., Krause D., Deans R., Keating A., Prockop D., and Horwitz E. (2006): Minimal criteria for defining multipotent mesenchymal stromal cells. The international society for cellular therapy position statement. Cytotherapy, 8:(4): 315317.

11. Theocharis, S. E., Margeli, A. P., Skaltsas, S. D., Spiliopoulou, C. A., \& Koutselinis, A. S. (2001). Induction of metallothionein in the liver of carbon tetrachloride intoxicated rats: an immunohistochemical study. Toxicology, 161(1-2), 129 138.

12. Xiang, H. et al. (2017) 'A new oleanolic acid derivative against $\mathrm{CCl}$ 4 -induced hepatic fibrosis in rats', International Journal of Molecular Sciences, 18(3), pp. 1-15. doi: 10.3390/ijms 18030553.

13. Soleimani, M., \& Nadri, S. (2009). A protocol for isolation and culture of mesenchymal stem cells from mouse bone marrow. Nature protocols, 4(1), 102.

14. Yildiz O, Can Z, Saral O, Yulug E, Ozturk F, Aliyazicioglu R, Canpolat S, Kolayli S. (2013): Hepatoprotective potential of chestn ut bee pollenon carbon tetrachloride induced hepatic damages in rats. Evid Based Complement Alternat Med.; 2013: 461478.

15. Yu F, Ji S, Su L, Wan L, Zhang S, Dai C, Wang Y, Fu J and Zhang Q. Adipose-derived mesenchymal stem cells inhibit activation of hepatic stellate cells in vitro and ameliorate rat liver fibrosisin vivo. Journal of the Formosan Medical Association (2015)114, 130-138. 
16. Ren H, Zhao Q, Cheng T, et al: No contribution of umbilical cord mesenchymal stromal cells to capillarization and venularization of hepatic sinusoids accompanied by hepatic differentiation in carbon tetrachloride induced mouse liver fibrosis. Cytotherapy 2010, 12(3):371-383.

17. Perkins, J. D. (2007) 'Techniques to ensure adequate portal flow in the presence of splenorenal shunts', Liver Transplantation, 13(5), pp. 767-768. doi: 10.1002/lt.

18. Giacoppo, S., Bramanti, P. and Mazzon, E. (2017) 'The transplantation of mesenchymal stem cells derived from unconventional sources: an innovative approach to multiple sclerosis therapy', Archivum Immunologiae et Therapiae Experimentalis. Springer
International Publishing, 65(5), pp. 363-379. doi:

19. Abdel aziz MT, EI Asmar MF, Atta HM, et al: Efficacy of mesenchymal stem cells in suppression of hepatocarcinorigenesis in rats: possible role of Wnt signaling. J Exp Clin Cancer Res 2011, 30:49.

20. Rabani V, Shahsavani M, Gharavi $M$, et al: Mesenchymal stem cell infusion therapy in a carbon tetrachloride-induced liver fibrosis model affects matrix metalloproteinase expression. Cell Biol Int 2010, 34(6):601-605.

21. Kim SJ, Park KC, Lee JU, et al: Therapeutic potential of adipose tissuederived stem cells for liver failure according to the transplantation routes. J Korean Surg Soc. 2011, 81(3):176-18.

Table 1 Serum ALT, AST, GGT and ALP activities in rats induced fibrosis and treated with MSCs.

\begin{tabular}{|l|c|c|c|c|}
\hline \multicolumn{1}{|c|}{ Group } & ALT & AST & GGT & ALP \\
\hline $\begin{array}{l}\text { Normal } \\
\text { control }\end{array}$ & $50.4 \pm 6.75^{\mathrm{dt}}$ & $61.5 \pm 10.05^{\mathrm{dt}}$ & $11.0 \pm 2.13^{\mathrm{dt}}$ & $122.2 \pm 13.95^{\mathrm{dt}}$ \\
\hline $\begin{array}{l}\text { CCL4- } \\
\text { injected }\end{array}$ & $400.3 \pm 18.59^{\mathrm{ct}}$ & $448.2 \pm 22.83^{\mathrm{ct}}$ & $55.9 \pm 5.37^{\mathrm{ct}}$ & $520.7 \pm 48.2^{\mathrm{ct}}$ \\
\hline $\begin{array}{l}\text { Stem cells } \\
\text { treated }\end{array}$ & $135.5 \pm 16.6^{\mathrm{cd}}$ & $154.9 \pm 14.07^{\mathrm{cd}}$ & $15.4 \pm 3.2^{\mathrm{cd}}$ & $233.3 \pm 27.16^{\mathrm{cd}}$ \\
\hline
\end{tabular}



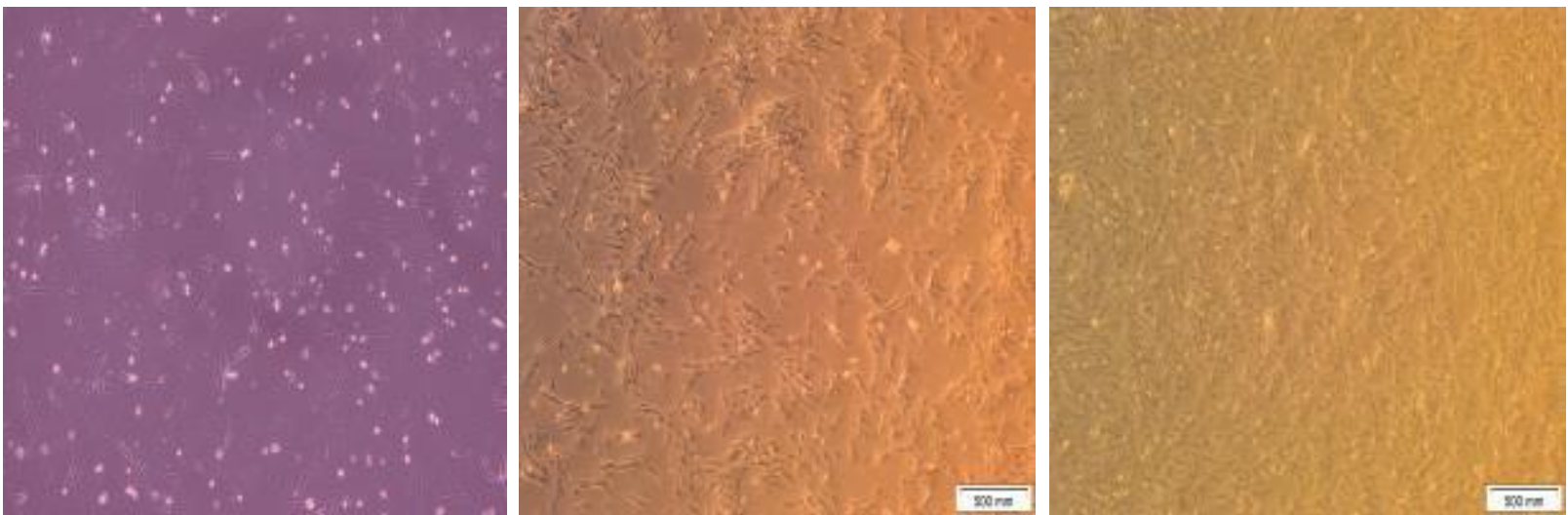

Figure 1: Inverted phase contrast microscopic images with $4 x$ magnification power showing spindle AD-MSCs adhered to the plastic surface of the flask after 3 days from isolation (A), 6 days from isolation (B), and after 10 days of isolation with high confluence (C).
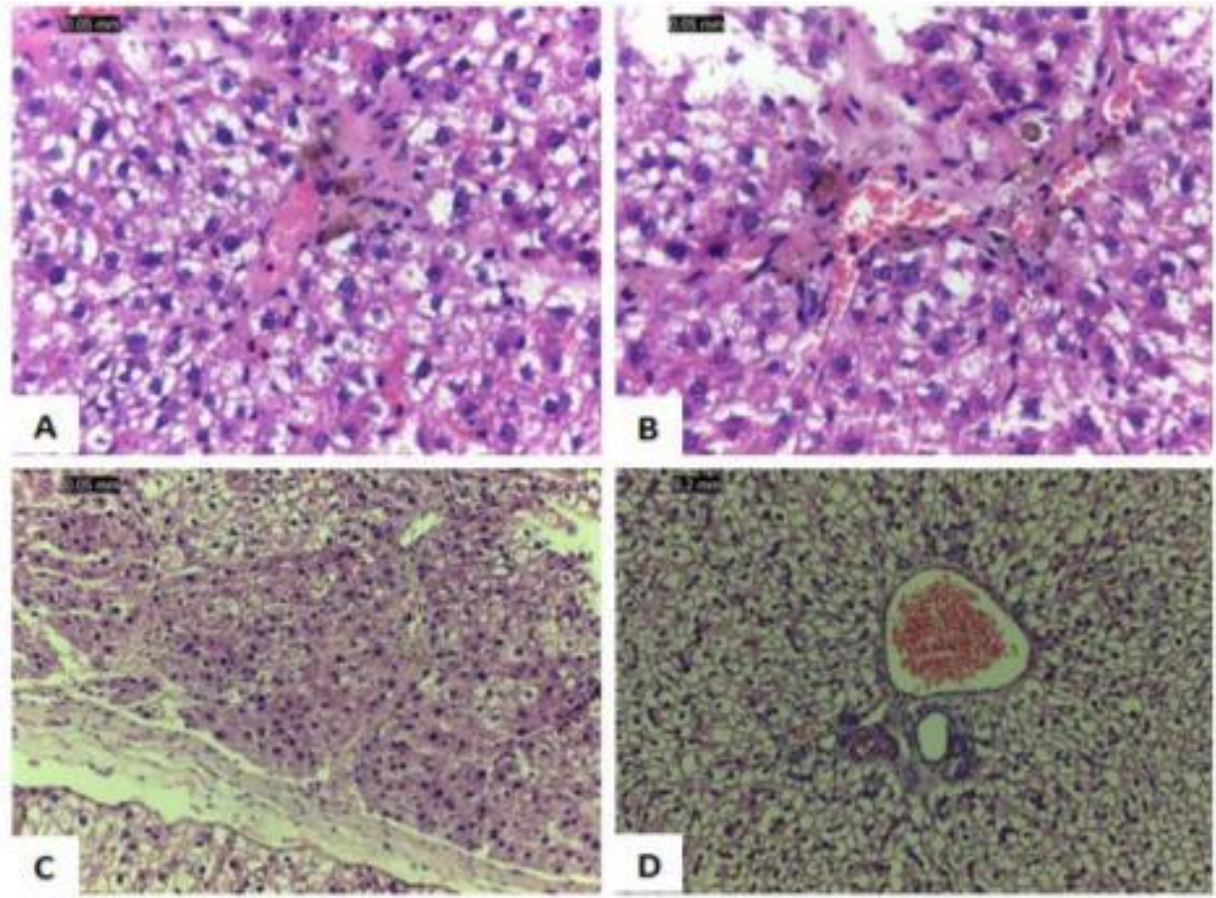

Figure 2: relieve of liver fibrosis after AD-MSCs injection. A: negative control liver shows that there was no pathological change in hepatic tissues. B: hepatic tissue revealed the presence of injected stem cells. C: hepatic tissues of untreated shows disturbed liver architecture with cloudy swelling of hepatocytes, fatty degeneration, and portal fibrosis. D: hepatic tissues of the treated group show minimal portal fibrosis (H\&E, X100). 